\title{
CHROMOSOMAL VARIATIONS AND THE FORMATION OF THE FIRST SPERMATOCYTE CHROMOSOMES IN THE EUROPEAN EARWIG, FORFICULA SP.
}

\author{
FERNANDUS PAYNE
}

SIXTY-FOUR FIGURES

During the months of September and October, 1912, I collected a number of specimens of Forficula in the vicinity of Würzburg. The species remain in doubt, but probably most of my specimens are auricularia. From the chromosomal history, one other species may be present in my material. The gonads were fixed in Flemming and Bouin and the sections stained with Haidenhain's hemotoxylin. A superficial study of the slides indicated that irregularities in chromosome distribution were present. Nothing further was done, however, until my return to Bloomington. Upon looking up the literature, I found that a number of investigators had worked on Forficula auricularia, but their results were not in agreement.

As early as 1885 Carnoy described the number of chromosomes in the spermatocyte divisions as varying from 10 to 14 . Two years later La Valette St. George ('87) described 12 in the first and 12 to 14 in the second spermatocytes. Sinety ('01) found no irregularities and gave the spermatogonial number as 24 and the spermatocyte 12. In two papers Zweiger ('06) works over the field in detail and finds the spermatogonial number 24 or 26 and the spermatocyte 12,13 or 14 . The observations of Stevens ('10) are more nearly in agreement with those of Sinety ('01). She finds the spermatogonial number 24 , the first spermatocyte 12 and usually 12 in the second, although 11 and 13 chromosomes are occasionally counted in this division. She also describes an unequal pair of idiochromosomes. The explanations which these authors offer are no more in agreement than their observations.

' Contribution from the Zoological Laboratory of Indiana University, No. 134. 
From these various descriptions and disagreements, it would seem that an excessively large number of errors have been made or that we really have irregularities in chromosome distribution. I believe the latter to be the case. In fact, my material shows this beyond a doubt and offers a plausible explanation for at least some of these irregularities. Stevens ('10) suggests that Forficula auricularia is a composite species, made up of several small species, which differ with respect to the number and behavior of the chromosomes. With this possibility in mind, I have studied the individuals singly and then compared the results. As we shall see, the differences within some individuals are as difficult of explanation as between different individuals.

\section{DESCRIPTION}

Specimen No. 29-2. In this specimen I found only one spermatogonial group which I was able to count. This showed clearly 24 chromosomes (fig. 1, A). The fact that the specimens were collected so late in the season accounts for the small number of spermatogonial divisions. A large percentage of the testes collected were full of mature spermatozoa. The first spermatocyte divisions show 12, 13 and 14 chromosomes (fig. $1, L$ and $M$; $14 ; N, 13$ and $O, 12$ ). By counting only clear metaphase plates, I found 18 cells with 12,13 with 13 and 3 with 14 chromosomes. These variations are found, not only within the testes of one individual, but, contrary to the observations of Zweiger ('06), they occur within a single cyst. Zweiger believed that a cyst arises from a single cell and hence all cells within the cyst contain the same number of chromosomes. He gives the spermatogonial number as 24 and 26 . The half or reduced number would be 12 or 13 . This, however, would not explain his 14 chromosome counts. According to his view such a group would have to arise from a spermatogonial cell with 28 chromosomes.

In my work a study of polar views failed to explain these variations, so I have resorted to a study of side views of metaphase plates, and believe I have found a true explanation. Why the chromosomes behave as they do thus causing these variations, I cannot say. Smear preparations would no doubt have helped 


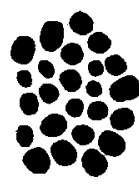

$A$

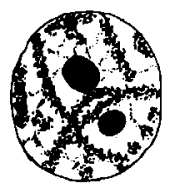

$B$

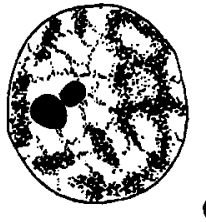

C

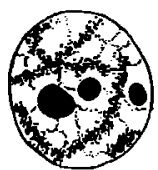

$D$

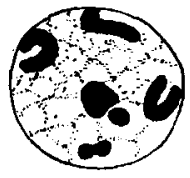

$\boldsymbol{E}$
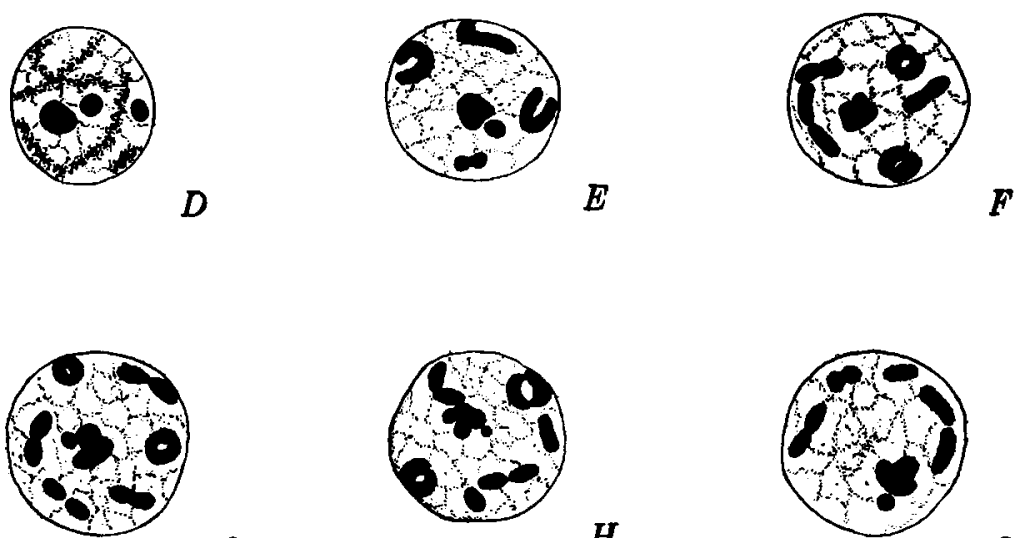

$G$

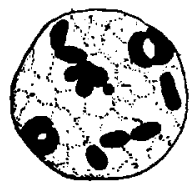

$H$
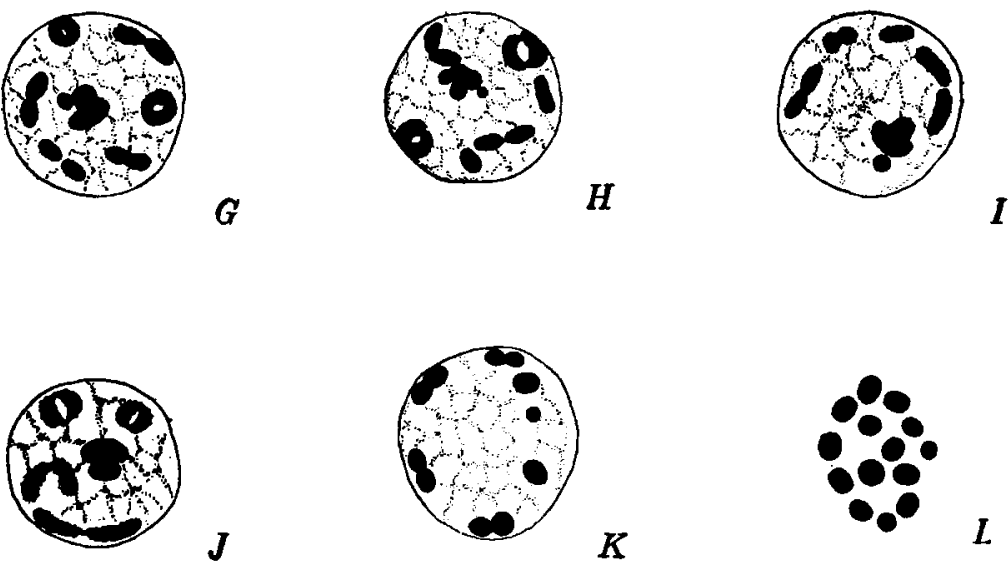

$K$
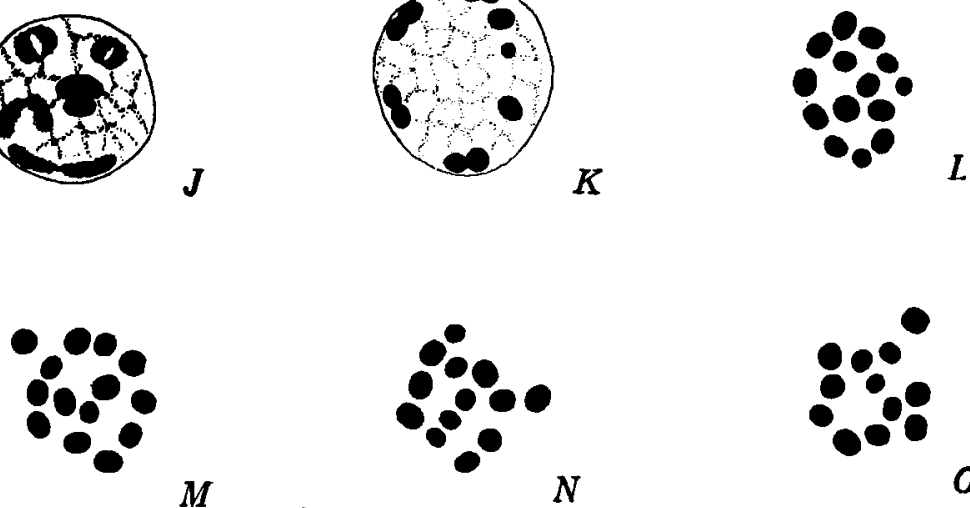

$M$

$N$

0

Fig. 1 Specimen 29-2 $A$, spermatogonial group with 24 chromosomes; $B, C, D$, early growth period, showing two or three black staining bodies; $E, F, G$, $H, I, J, K$, early prophases, demonstrating that the unequal pair arises from the dark staining nucleolus; $L, M$, first spermatocyte, polar view, showing 14 chromosomes; $N, 0$, first spermatocytes with 13 and 12 chromosomes respectively. 
in this study, but as no other material is available, my study is limited to sections. I realize that a study of serial sections of side views of a metaphase plate is beset with danger, as the knife may cut chromosomes so as to make them appear as two. However, this has not been such a serious difficulty as it might seem and in the following description I feel reasonably sure I have not made a mistake in this way. Further, these observations have been confirmed by a study of cells in which all the chromosomes are present in a single section. The greatest danger would be in cutting a double chromosome into its two components so as to make it appear as two single chromosomes. In my study of single chromosomes I have been very careful, when two or more are present in a single cell, to see that they do not lie opposite, that is, if the cell were reconstructed the two single ones would not fit together to make a bivalent.

Side views of metaphase plates with 12 chromosomes show all of them to be bivalent and dumb-bell-shaped (fig. 2, $L, M, N$ and $O$.) Stevens ('10) described in Forficula auricularia a pair of slightly unequal idiochromosomes. I find here also one of these 12 bivalents (fig. 2, $D, i$ ) is slightly unequal. Sometimes no size difference is visible in any of the bivalents and in no case do I find the difference as great as that described by Stevens. Since I have not been able to compare male and female groups, I cannot state definitely whether this unequal pair is related to sex. Even if I had the material for comparison, it is doubtful whether it would yield results, as the size difference is so small. I hesitate all the more in saying definitely that it is related to sex since the recent paper of Carothers ('13) describing among the autosomes an unequal pair.

Side views of metaphase plates with 13 chromosomes show 11 bivalent and two single ones (fig. 2, $D, E, F, G$, serial sections of one cell and $H, I, J, K$, of another). This indicates clearly, it seems to me, that two spermatogonial chromosomes have failed to conjugate at synapsis or have conjugated and then separated. A polar view of such a group looks very different from one with 12 , yet the two are the same, the difference being that the components of one bivalent have remained separate in 


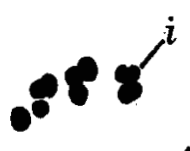

A

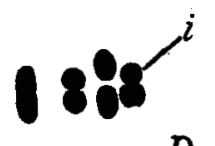

D

sor

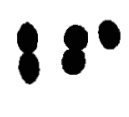

is

$L$

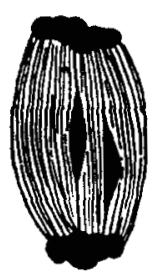

$P$

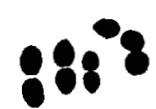

B

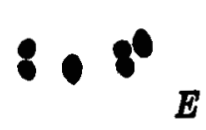

88

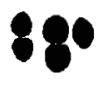

I

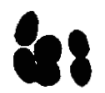

M

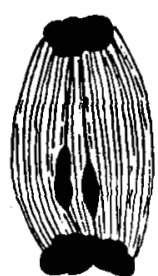

$Q$
F

28

C

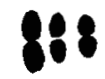

$\theta$

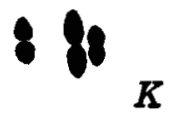

8880

N

0

Fig. 2 Specimen 29-2. $A, B, C$, serial sections, side view, of a single metaphase plate, first division with 14 chromosomes, showing that four of these are univalent and 10 bivalent; $D, E, F, G$, serial sections of a metaphase plate with 13 chromosomes showing 11 biavalent and two univalent ones; $H, I, J, K$, same as $D, E, F, G ; L, M, N, O$, serial sections of a metaphase plate with 12 chromosomes showing that all of them are bivalent; $P, Q, R, S$, anaphases of the first maturation division showing the behavior of the single chromosomes.' 
one case and have fused in the other. A few cells show 14 chromosomes. Side views of such cells show that ten of these are bivalent and four univalent. In this case the components of two bivalents have remained separate and the group as a whole is the same as the one where 12 and 13 chromosomes appear in polar views.

The interesting thing about these univalent chromosomes is not the fact that they are univalent, but their irregular behavior in the two divisions which follow. So far as I know, with the exception of the supernumerary chromosomes of Metapodius and Diabrotica, the behavior of any univalent chromosome in the two maturation divisions is regular, and such chromosomes divide in one or the other division. The rule is for bivalent chromosomes to divide twice and univalent chromosomes once. We would expect then these univalent chromosomes in Forficula to divide in one maturation division and not in the other. In the first maturation division I find that they may or may not divide and, whatever happens to them, they always lag behind the others. Figure 2, $S$ shows both of them divided; $R$ shows one divided, the other undivided. In $Q$ it seems that both are passing undivided to one pole. In $P$ both are elongated and it is impossible to say just what disposition will be made of them. Sometimes they become more drawn out, and in such cases as figure 4, $N$ (a different individual), it seems very doubtful whether one lagging chromosome will ever reach either pole. These lagging chromosomes are the ones which Zweiger calls 'accessorische Chromosomen.' I have seen only one anaphase with four lagging chromosomes and it was not suitable for drawing. Hence I have not been able to make out the distribution of the univalents in the 14 chromosome groups. From this irregularity in the behavior of these single chromosomes, it will be seen that the number of chromosomes in the second maturation division will vary. This is the case, and by actual count of polar views, clear metaphase plates, I have found nine cells with 11 chromosomes; 65 with $12 ; 23$ with 13 and four with 14 . For these variations see figure $3, B, C, 14$ chromosomes; $D, E, F, 13$ chromosomes; $G, H, 12$ chromosomes and $I, J, K, 11$ chromosomes. 

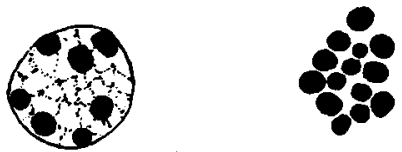

$A$

$B$
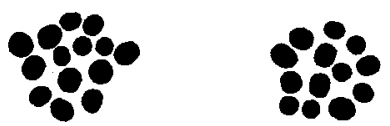

C

$\boldsymbol{D}$
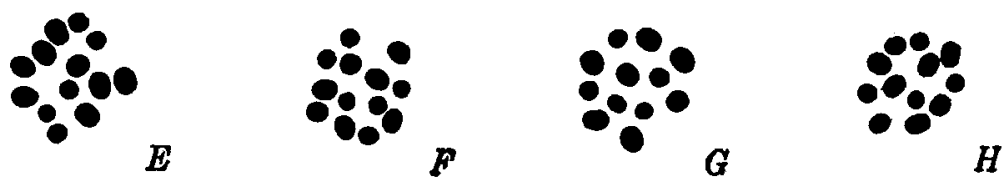

$H$
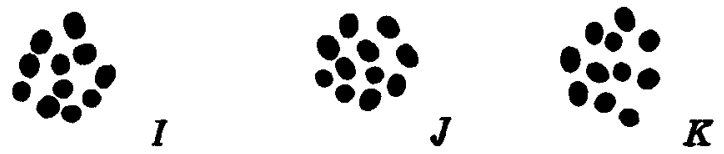

:0\%:

$\boldsymbol{K}$

$L$
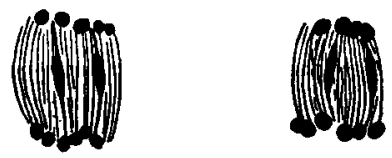

$M$

$N$

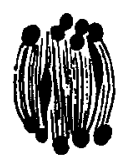

0

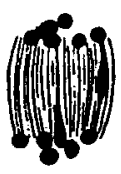

$\boldsymbol{P}$

Fig. 3 Specimen 20-2. $A$, a resting nucleus between the first and second spermatocyte divisions; $B, C$, second spermatocyte divisions, polar views, 14 chromosomes; $D, E, F$, the same with 13 chromosomes; $G, H$, the same with 12 chromosomes; $I, J, K$, the same with 11 chromosomes; $L, M, N, O, P$, anaphases of the second division, side view, showing the behavior of the lagging chromosomes.

If there are 12 bivalents in the first division, all of them divide so that each secondary spermatocyte receives 12 chromosomes, and by actual count it is seen that more than two-thirds of them receive this number. When there are 13 chromosomes in the first division, two of these are univalent and divide irregularly. If both divide, each resulting cell receives 13 chromosomes; 
if one divides and the other passes to one pole undivided, one cell will receive 12 and the other 13 chromosomes; if one passes to one pole and the other to the second pole undivided, each resulting cell will receive 12 chromosomes; lastly, if both single chromosomes pass to one pole undivided the result is one cell with 11 chromosomes and one with 13 . Cells with 14 chromosomes are rather rare and, as shown above, are composed of ten bivalent and four univalent chromosomes. The irregular division of these four chromosomes might cause the variations, ranging from 10 to 14, the number which Carnoy ('85) actually described. Unfortunately my material does not show sufficient anaphases to demonstrate the distribution of them.

There is a short resting stage between the first and second maturation divisions (fig. $3, A$ ). In the anaphases of the second, some of the cells show lagging chromosomes. While the evidence is not direct, these lagging chromosomes are no doubt the univalent ones which behave irregularly in the first maturation division. Judging from such figures as $3, M, N, O$, and $P$, here again the behavior is irregular, and the spermatids undoubtedly receive numbers varying from 11 to 14 and perhaps from 10 to 14 chromosomes. All of these spermatids, I believe, develop into mature spermatozoa, as I have seen no sign of their degeneration. Whether all such spermatozoa function is impossible to say with the limited amount of material at my command. I hope to be able in the near future to obtain additional material for the study of this and other questions which remain unsolved.

A few words concerning the growth period may not be out of place before leaving this specimen, as it seems to be clearer here

Fig. 4 Specimen 29-3. $A, B$, spermatogonial cells with 24 chromosomes each; $C, D$, oogonial cells which have been included in this plate and which were the only ones which could be counted, 25 chromosomes (They were not very clear and I lay no weight on this evidence); $E, F, G$, serial sections, side view, of a metaphase plate of the first division with 13 chromosomes showing 11 bivalent and two univalent; $I, J, K$, serial sections of a metaphase plate with 12 chromosomes, all of which are bivalent; $H$, metaphase plate, pole view, first division, 12 chromosomes; $L$, metaphase plate, 13 chromosomes; $M, N, O$, anaphases of the first maturation division showing distribution of the univalents; $P, Q$, second spermatocyte divisions, metaphase plates, 13 chromosomes; $R, S$, the same with 12 chromosomes. 
FORMATION OF THE FIRST SPERMATOCYTE CHROMOSOMES 567

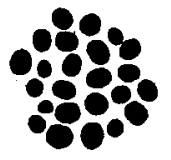

$A$

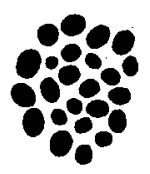

$B$

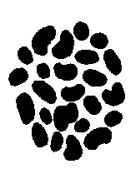

C

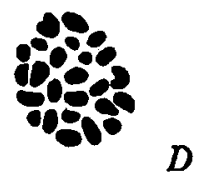

$28{ }_{E} \quad 898$

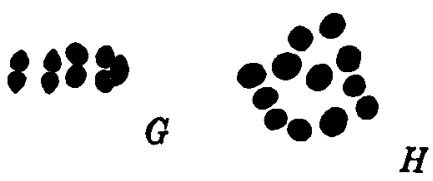

188.

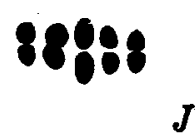

88

K

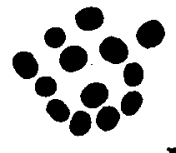

$L$
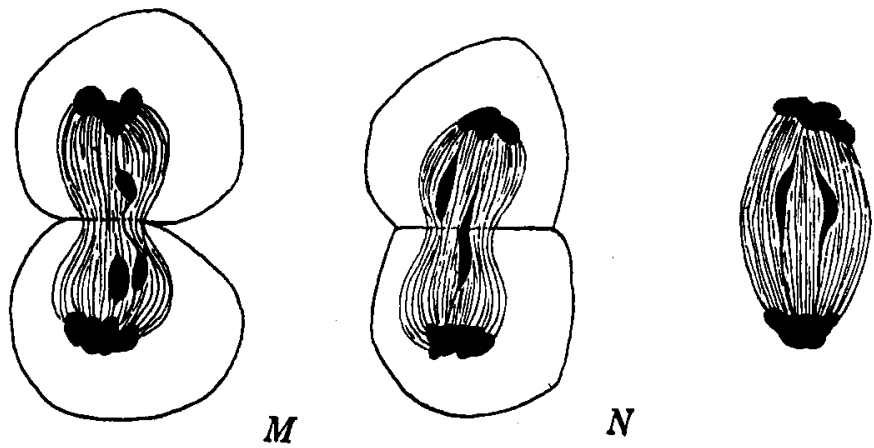

$N$

0
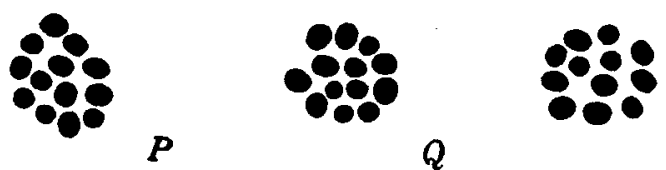

$Q$

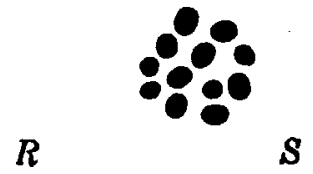

Figure 4 
than in any of the others. Shortly after the last spermatogonial division and throughout the entire growth period, two and sometimes three chromatin nucleoli are present in the nucleus. In the prophases of the first spermatocyte division only one large nucleolus remains. Whether the second and third one disappear or whether all of them fuse, I cannot say. Stevens ('10) describes the second and third bodies as plasmosomes, but with hemotoxylin all of them stain alike. At any rate, from the single nucleolus there arises in late prophases the unequal pair of chromosomes. This is shown particularly well in figure $1, J$. Most of the time a third small body is either in contact with them or lying very close (fig. $1, F, G, H, I$ ). What this small body is I do not know, but believe it is not a chromosome as it is smaller than any of those which appear in the first spermatocytes. It persists until the late prophases (fig. $1, K$ ) and then can be traced no further. It will be noticed in figure $1, J$, that the size difference between the components of the unequal pair is greater during the early prophases than in metaphase.

Zweiger explains these irregularities in number by assuming that in cells with 12 chromosomes no accessory is present; in cells with 13, one accessory is present and in cells with 14, two accessory chromosomes are present. He further assumes that the accessory chromosomes divide in both maturation divisions, something which no accessory chromosome has ever been observed to do. I am using the word 'accessory' in the sense that it has been used by various authors in the recent work on chromosomes which are related to sex. It is a spermatogonial chromosome which has no mate with which to pair at synapsis and which appears in the spermatocyte divisions as a univalent chromosome and hence divides in only one of them. The spermatozoon which receives this chromosome is female producing and the other is male producing. It is readily seen that $Z_{\text {weiger's }}$ 'accessorisches Chromosom' is not of this type. He describes his 13 chromosome group as containing one accessory chromosome and assumes that such groups arise from spermatogonial cells with 26 chromosomes. Hence all 13 would be bivalent. My observations show clearly that when 13 chromosomes are present, 
two of them are univalent and that their behavior in the maturation divisions is irregular.

As previously stated, Stevens finds 12 chromosomes in the first spermatocyte division and usually 12 in the second, although 11 and 13 are sometimes present. She accounts for 13 by assuming that the small idiochromosome may sometimes divide precociously. She sees no way of explaining the 11-group except by assuming that both idiochromosomes occasionally pass to one pole undivided in the first spermatocyte division. Later, I shall attempt to show that in some individuals the 13-group in the second division may be caused by the precocious division of one small chromosome.

Specimen 29-3. This is very similar to 29-2. Two spermatogonial counts show 24 chromosomes each (fig. 4, $A$ and $B$ ). In the first division (fig. $4, H$ and $L$ ), I find 17 cells showing clearly 12 chromosomes and nine showing 13 . Side views of metaphase plates again show 2 univalents in the 13-chromosome group (fig. 4, $E, F, G$ ). Anaphases also show the lagging chromosomes in some of the cells. Figure $4, M$ and $N$ are late anaphases in which the cell plate has begun to form. In $M$, there is no doubt that one univalent has divided while the other is passing to one pole undivided. In $N$, one chromosome is passing to one pole undivided while the other is very much drawn out and it seems doubtful whether it will reach either pole. As in 29-2, the irregular behavior of these univalent chromosomes causes variations in the number of chromosomes in the second spermatocytes. The counts here gave 63 cells with 12 chromosomes and 15 with 13 . It seems rather strange that no cells with 11 were present as these might be expected from what was found in 29-2. Four other specimens show the same irregularities as the two above. They did not contain as many dividing cells, however. Specimen $27-1$, in the first division, showed one cell with 12 chromosomes, two with 13 and three with 14; in the second division two cells with 12 chromosomes and two with 13. Specimen $27-2$, gave in the first division three cells with 12 chromosomes; in the second division 26 cells with 12 chromosomes and four with 13 . In specimen $27-3$, I found 15 
cells with 12 chromosomes and two with 13 in the first division; in the second division, 20 counts showed 12 in all. From 12 counts of the first division in specimen $27-4$, there were four with 12 chromosomes, three with 13 and one with 14 . In the second division 22 counts were made. Fourteen of these showed 12 chromosomes, seven showed 13 and one showed 14.

Specimens 34-1. Stevens ('10) accounted for the occasional appearance of 13 chromosomes in the second division by supposing that the small idiochromosome sometimes divides precociously. In this specimen the evidence is in favor of a similar interpretation. Only four first division figures which could be clearly counted were present. All of them contained 12 chromosomes (fig. 5, $I$ and $J$ ). In the second division, 125 counts gave 115 with 12 chromosomes and 10 with 13 . If the 12-group is studied carefully, it can be seen that there are four chromosomes which are noticeably smaller than the others (fig. 5, $A, B, C, D$ ). A fifth one is present which sometimes appears about the size of these four, but more often it is just a little larger, intermediate between them and the larger chromosomes. In the 13-group five and sometimes six chromosomes are smaller than the others (fig. 5, $E, F, G, H$ ). Among these five or six, two are considerably smaller than the others, and it seems very probable that these two small ones have arisen by the precocious division of one of the smaller chromosomes which appears in the 12-group. Whether the chromosome which divides precociously is the small one of the unequal pair, is impossible to say. In fact, I am inclined to think that it is not, since the irregularities in the other specimens are not caused by this pair.

Specimens 31-1, 31-2, and 26. The latter two show no irregularities in either maturation division. Since 31-1 shows only one irregularity I have placed it in the same group. In this specimen, 39 counts of the first division showed 12 chromosomes. In the second division, 69 counts gave 12 chromosomes and one 13 , the only irregularity observed. In $31-2,34$ counts of the first division gave 12 chromosomes and 70 counts of the second gave the same number. In 26, three cells of the first division gave 12 chromosomes and 22 counts in the second division also 


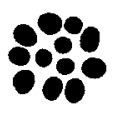

A

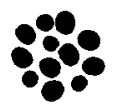

$B$

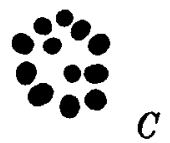

$C$

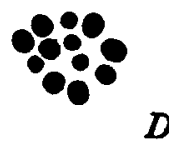

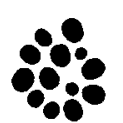

$E$
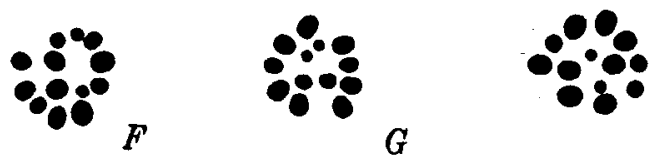

$G$

$\boldsymbol{H}$
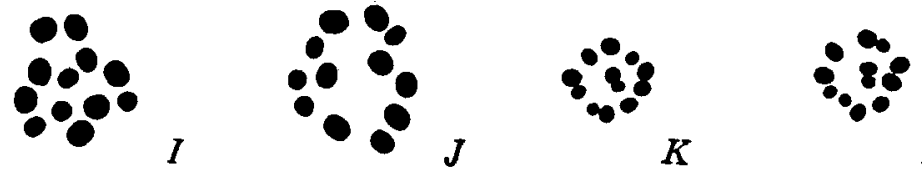

$K$

$L$

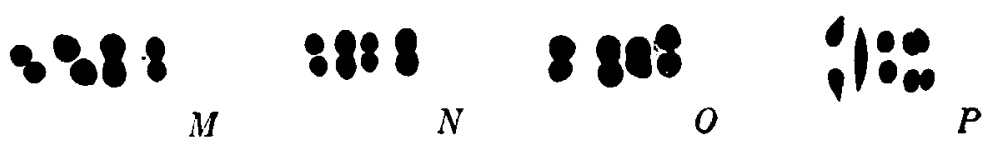

Fig. 5 Specimen 34-1. $A, B, C, D$, second spermatocyte divisions, pole views, showing 12 chromosomes; $E, F, G, H$, the same with 13 chromosomes; $I, J$, metaphase plates, first spermatocyte division, 12 chromosomes; $K, L$, second division anaphase, polar views, of both chromosome groups from the same spindle; $M, N, O$, serial sections, side views, of a metaphase plate of the first division showing that all shromosomes are bivalent; $P$, early anaphase of the second division showing one elongated chromosome.

gave 12 chromosomes. These specimens show clearly that by working on a limited amount of material, an observer might be led to believe that no irregularities were present. It is only by a comparative study of a large number of individuals that we may hope to reach a true solution of these difficulties. 
Specimen 34-Q is the most puzzling individual of them all. The chromosome distrubution is somewhat different from the others and this leads me to suspect that it may be a different species. The most striking variations are in the spermatogonial divisions. Two different cysts were found in division and variations were present in both. Among 33 counts of clear metaphase plates there were nine with 24 chromosomes, 16 with 25 , seven with 26 and one with 27; (for these variations see fig. 6, $A, 27$; $B, C, D, 26 ; E, F, G, H, 25$ and $I, J, 24$ chromosomes). I am at a loss to explain these variations and certainly will not draw any conclusions from them. However, a few suggestions which the facts warrant may not be out of place. As there are a number of multipolar figures in the cyst, it is possible that these divisions may be pathological. Secondly it is possible that the chromosomes which behave irregularly in the spermatocyte divisions may also behave irregularly in the spermatogonial divisions. Thirdly, all counts (45) of the first spermatocyte division with the exception of one-and as we shall see this is really not an exception-show 13 chromosomes. Twelve of these 13 are bivalent and one single (fig. 6, $L, M, N$, three metaphase plates which have been smashed to cause the chromosomes to lie flat as in a smear preparation). Figure $7, A, B, C$, are serial sections of a single cell, showing likewise 12 bivalent and one univalent chromosome. In case there are 14 present, 11 are bivalent and three univalent (fig. 7, $E$ and $F$ ). So, as in the case of the other individuals, the two groups are in reality the same, although they appear different in polar views. The chromosomes then in the first division must have come from a spermatogonial cell with 25 chromosomes, 24 of them uniting two by two to form

Fig. 6 Specimen 34-2. $A$, spermatogonial group with 27 chromosomes; $B, C, D$, the same with 26 chromosomes; $E, F, G, H$, the same with 25 chromosomes; $I, J$, the same with 24 chromosomes; $K$, growth period showing nucleoli; $L, M, N$, first maturation divisions, metaphase, which have been smashed as in a smear preparation, showing 13 chromosomes, 12 of which are bivalent and one univalent; $O$, first division, polar view, 14 chromosomes; $P$, first division, 13 chromosomes ( $O$ and $P$ are found in the same cyst) $Q, R$, anaphases, polar view, from the same spindle; $Q, 13$ chromosomes and $R, 12 ; S, T$, second spermatocyte divisions showing 13 and 12 chromosomes respectively. 
FORMATION OF THE FIRST SPERMATOCYTE CHROMOSOMES 573

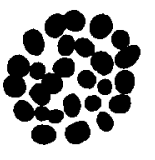

$A$

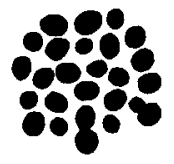

$B$

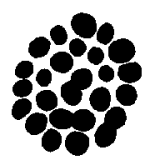

$C$

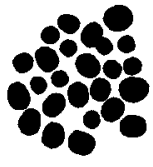

G

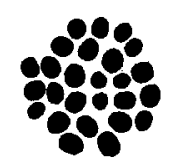

$D$

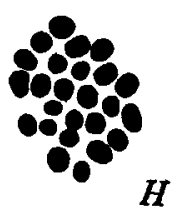

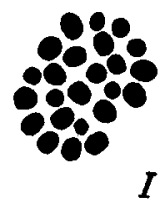
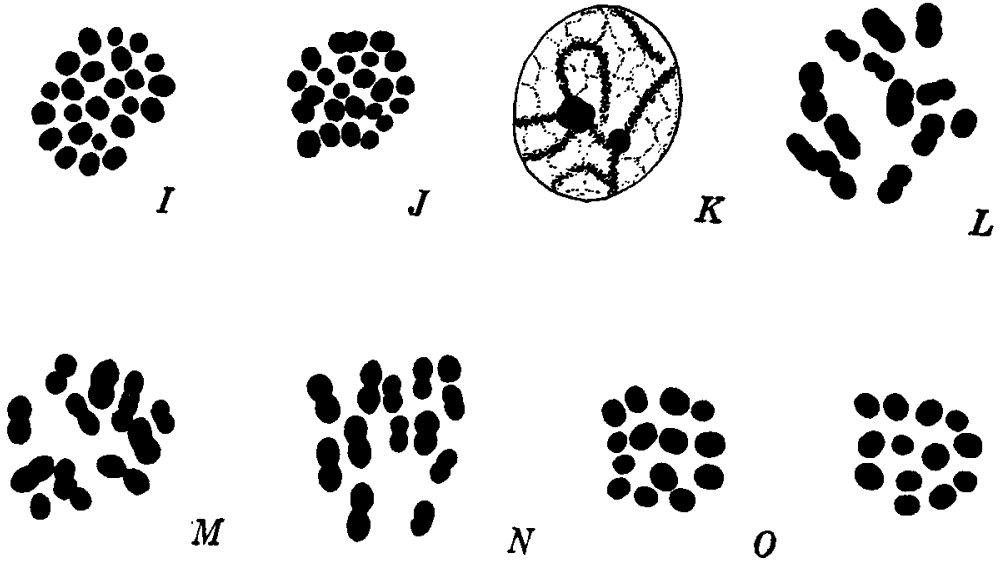

0

$P$
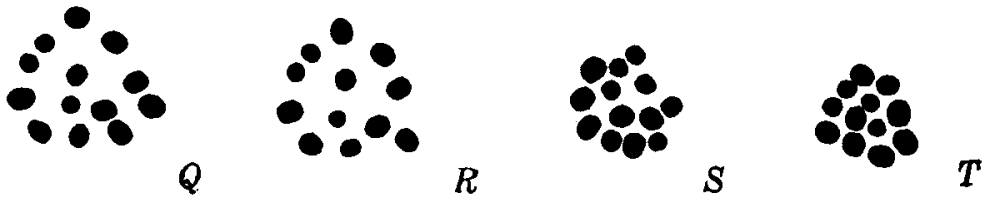

Figure 6 
8288

A

B

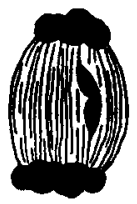

D
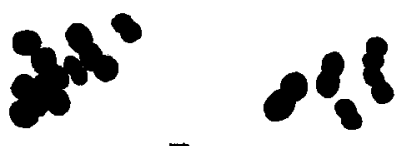

$\boldsymbol{E}$

F
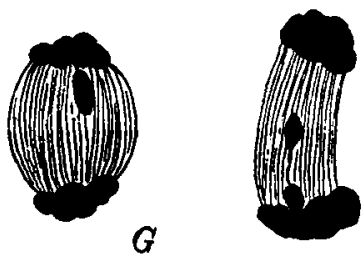

H
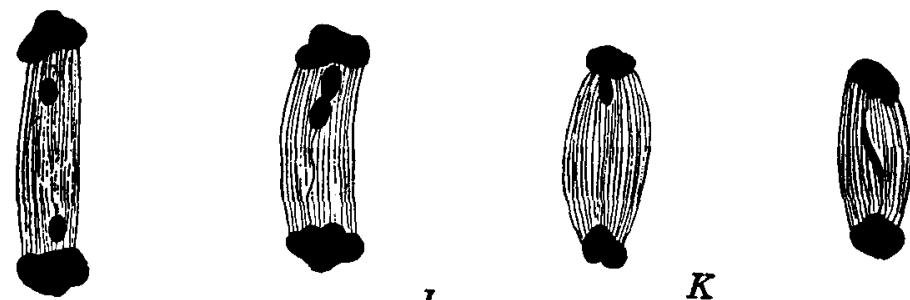

K

$L$

Fig. 7 Specimen 34-2. $A, B, C$, serial sections of a metaphase plate of the first division with 13 chromosomes, 12 of which are bivalent and one single; $E, F$, serial sections, first division, of a cell with 14 chromosomes, 11 of which are bivalent and three univalent; $D, G, H, I, J$, anaphases, first spermatocyte division, showing behavior of the single chromosome; $K, L$, anaphases of the second division showing a lagging chromosome here also.

the 12 bivalents and the other remaining single. From the spermatocyte chromosomes then, it would seem that 25 is the true spermatogonial number and the others (24, 26 and 27) are abnormal or at least not functional.

In this specimen I have not been able to make out an inequality in the two parts of any of the bivalents. Even though no size difference is recognizable, a pair corresponding to the unequal pair in the other individuals may be present. The nucleoli in the growth period look very much as they do in the other speci- 
mens and there the unequal pair arises from the nucleolus in the prophases of the first spermatocyte division. A study of side views of metaphase plates of the first division indicates that we might have a case of a single unpaired idiochromosome. This seems very doubtful, however, since the behavior of the single chromosome in the maturation divisions is irregular. Its behavior is similar to that of the single chromosomes in the other individuals. Figure $7, D, G, H, I$ and $J$ are anaphases of the first division and, I think, show clearly that this chromosome may pass to one pole undivided $(G)$; that it may divide, one part passing to one pole and one to the other $(I)$, or that it may constrict as if to divide and in this manner pass to one pole $(J)$. Counts of the second division, metaphase plates, show 34 cells with 13 chromosomes and 34 with 12 . This indicates an approximate equal distribution of the single chromosome. In anaphases of the second division (fig. $7, K$ and $L$ ) a single lagging chromosome is likewise present and no doubt it may or may not divide. My figures do not show it in division, but Zweiger ('06) and Stevens ('10) show a lagging chromosome in the second division which divides. Figure $7, L$, is interesting in that it shows this chromosome very much elongated. In such cases it seems very doubtful whether it ever reaches either pole.

\section{Formation of the first spermatocyte chromosomes}

During the greater part of the growth period, and possibly all of it following synapsis, the chromatin threads appear double and made up of two rows of granules (plate 1, fig. 1). From these chromatin threads the dumb-bell-shaped spermatocyte chromosomes are formed. One of the intermediate stages in this transformation is a more or less typical ring, and it is the formation of this ring with which $\mathrm{I}$ am principally concerned. Two methods of ring formation have been described. Let us leave out for the present the question whether the longitudinally split thread is formed from chromosomes which have united end to end or side by side. One method is by the bending of the thread until the free ends come in contact. This method has been 
described by Sutton ('02) in Brachyostola and Davis ('08) for several species of Orthoptera. Both these authors describe an end to end conjugation. The second method has been described by the Schreiners ('06) in Tomopteris, by Morse ('09) in Periplaneta and by others. In this case the ring is formed by the opening or moving apart of the two parallel parts of the split thread in the middle region, the ends of the two parts remaining in contact. These authors assume a side by side conjugation of maternal and paternal elements.

In Forficula, Zweiger describes ring formation as arising by the bending and coming together of the two ends of the chromatin thread, or what I may designate briefly as the bending process. This ring in later stages condenses into a dumb-bellshaped chromosome. As he believed that the paternal and maternal chromosomes united end to end in synapsis, each part of the dumb-bell represented a single spermatogonial chromosome. Further, as the two parts separate, the first division, "according to this scheme, would be reductional. Stevens ('10) describes no complete rings but finds only U's and V's. She believed the two ends of the $U$ never come together, but straighten out again as condensation takes place. She also believed with Zweiger that telosynapsis takes place and that the first division is reductional.

My preparations of Forficula show clearly both methods of ring formation. Further, the rings are complete and not merely U's as described by Stevens. In fact, Zweiger's figures indicate that both methods are present. In his figure 60 , which is supposed to show the various stages of ring formation and the condensation of this ring into a bivalent, it is a long jump from ' $d$ ' to ' $e$.' In fact, I think there is no connection between them. If we begin at ' $\mathrm{d}$ ' and read in the opposite direction, ' $d, c, b, a$,' it will be seen that the split segment is opening up, as if in the initial stages of ring formation by splitting. I have seen no such irregular chromosomes as his figures ' $f, g$, $h$,' and hardly believe they occur in properly fixed material, although the two parts of the bivalent do bend around as he figures. While we have had both methods of ring formation described, Forficula, so far 
as I know, gives the first example in which both methods are found in the same individual.

As previously stated, the doubly split chromatin threads remain throughout at least the greater part of the growth period (plate 1, fig. 1). I have not been able clearly to follow the pairing of the chromosomes in synapsis, and cannot say whether the two parts of the split thread are maternal and paternal elements which have conjugated side by side or whether the split is a division of single chromosomes which have united end to end. In such rings as figures 10 and 11 , plate 1 , there is no indication of the point where the two chromosomes join. Perhaps it appears later, but then the rings become lost among the others and it is impossible to trace them. In the early prophases, some of these threads open out, forming rings as shown in figures 2 to 11 , plate 1. I have studied this point very carefully, being somewhat reluctant to believe that both methods could be present in the same species, but after going over the slides again and again, I have become convinced that such is the case. Plate 1, 12 to 17 , shows various stages in the bending and twisting of these threads as they open out into rings.

Ring formation by bending is much clearer and here I have been able to trace the process in a number of different chromosomes. By careful study it is possible to recognize individually some of the chromosomes during this process of ring formation. This makes it possible to trace practically every step in the process and I have figured a complete series in the case of four chromosomes. Plate 1, figure 18, shows one of these chromosomes which can be distinguished by its shape and size. Figures 19 to 21 show clearly the formation of the ring by bending, while figures 22,23 and 24 show the steps in the transformation into the chromosome of the first spermatocyte. By this series it is clearly seen that the composition of the bivalent chromosome (24) is the same as if the chromosome figured in 18, had condensed into a bivalent without passing through the ring stage. The split then in 18 is the line of the first maturation division. Whether this division is reductional, as believed by Zweiger and Stevens, I cannot say, as I do not know how the chromosomes 
paired at synapsis. These authors believed that an end to end pairing took place, but so far as I can see they have no convincing evidence for such a conclusion. Much of our work on the question of the reductional and equational divisions is worse than worthless, because of the fact that writers have not considered the question of synapsis. It has been shown by Wilson and others that one pair of chromosomes may divide one way while another pair is dividing another way. How then, can we be sure of reductional and equational divisions without having traced the stages in synapsis and in the formation and division of the spermatocyte chromosomes? A second chromosome is shown in plate 1 , figure 25 , and the various stages of bending into a ring in figures 26 to 30 . It is interesting that the rod and the ring in this case show no indication of the future division. A third chromosome in which I have given a more complete series of stages of bending is shown in plate 2, figure 1. The stages of transformation are given in figures 2 to 10 . Later stages in the transformation of this ring could not be followed. A fourth chromosome which is rather remarkable in having an identification mark is shown in plate 2, figure 19. This is the large chromosome in this figure and its peculiar characteristic is the presence of two more or less oval bodies at the division point. In the prophases these bodies usually stain more intensely than the rest of the chromosome. Just what they mean, if anything, I do not know. In late stages of condensation they are lost to view. By means of these bodies, which are present in this chromosome and so far as I have been able to make out in no others, the chromosome can be easily followed in its transformation. Sometimes it is joined end to end with another chromosome (plate 2 figure 20). Another interesting fact in connection with this chromosome is that it may form a typical ring by bending (plate 2, figs. 21-25) or it may occasionally condense into a bivalent without passing through the ring stage (plate 2, figures 26 and 27). Three small chromosomes are recognizable in the late prophases. These are shown in plate 2 , figure 11. They also may form a ring (12 and 13) or may condense into the bivalent without ring formation (14 and 15). 
These facts are somewhat contrary to the view expressed by Baumgartner ('04) for Gryllus. In several species of this genus he describes each chromosome as having a definite shape and definite method of condensation into the spermatocyte chromosome. In Forficula, as shown above, some of the chromosomes may or may not pass through the ring stage. The rule however, seems to be the ring formation. Baumgartner brings his facts to the support of the hypothesis of the genetic continuity of the chromosomes, and I think rightly so. I do not consider the fact that a chromosome may or may not pass through the ring stage as evidence against such an hypothesis. The end result is the same in either case and I do not see how an occasional variation by the omission of a bend in the chromosome can be used as evidence against the hypothesis. No such rigid demands are made of any other hypothesis and certainly we have no laws of development or behavior without their occasional variations. If variations are found in what may be considered laws of development why is such rigidity demanded of a working hypothesis?

\section{DISCUSSION}

We have seen that the chromosomal variations in Forficula are different from any which have been previously described, and they can be explained without the assumption that Forficula is a composite species made up of several smaller ones. For the discussion, let us leave out of account the spermatogonial variations described in specimen 34-2, as they may be pathological. Restricting ourselves then to the spermatocyte divisions, we find not only variations in number, but also that some of the chromosomes behave irregularly in these divisions. The variations in number, as I have shown, are caused by the failure of some of the spermatogonial chromosomes to pair at synapsis, and hence such chromosomes appear in the spermatocyte divisions as single or univalent instead of bivalent chromosomes. From what we know of the behavior of chromosomes, we should expect these univalent ones to divide in one of the two maturation divisions and not in the other. In Forficula the behavior of these chromo- 
somes is so irregular that I cannot say whether this rule is followed. Lagging chromosomes are seen in both divisions. In the first they may or may not divide. In the second they become very much elongated and while I have not seen them dividing, Zweiger ('06) and Stevens ('10) described lagging chromosomes in the second division which do divide. In some cases these lagging chromosomes become so drawn out that it seems doubtful whether they ever reach either pole of the spindle. Perhaps a failure to conjugate in synapsis is understandable, but the reason for the irregular behavior of the single chromosomes is not so clear. The only case approaching these irregularities is found in the supernumerary chromosomes of Metapodius and Diabrotica, but here such chromosomes are supposed to be functionless and on the road to degeneration.

I do not wish to draw any conclusions from the above observations, as the amount of material studied is too small. It might be well, however, to point out the principal questions which need further study. First, do the spermatids which receive 11, 12, 13 and 14 chromosomes become functional spermatozoa? Secondly, if so, do we find variations in the spermatogonial and oogonial number among different individuals of the species? Thirdly, if the spermatogonial and oogonial number is kept constant, what is the means of regulation? One other important problem which may be solvable in this material deserves mention. For some time it has been a disputed question whether the longitudinal split which appears in the chromatin thread following synapsis, is due to separation of maternal and paternal elements which have previously conjugated side by side, or whether it is a longitudinal splitting of chromosomes which have united end to end. In Forficula some of the chromosomes remain single and, so far as I have been able to make out, behave during the growth period as the bivalent autosomes. It seems to me that it may be possible to distinguish these single chromosomes from the double ones, at least in the early prophases of the first division, and if so, a comparison between the presence or absence of a longitudinal split in these single ehromosomes with the same in the double chromosomes, would prove of interest and perhaps give us some light on the question of synapsis. 
The fact that two methods of ring formation are present in Forficula might lead us to suspect that two methods of conjugation may be present or that we have some of the spermatocyte chromosomes dividing reductionally in one division and some in another. However, I cannot say definitely whether such is the case, as in ring formation by the opening up of the two parts of a longitudinally split thread, it is impossible to say exactly where the division occurs in the ring. Presumably it occurs where the ends of the double thread remain attached, but this is uncertain since all indications of this point of juncture are lost in later stages of condensation (plate 1, figures 8 to 11). Also it is impossible to say whether the cross division in such figures as shown in plate 1 , figure 18 , is reductional or equational, since it is not clear whether the chromosomes have conjugated end to end or side by side.

\section{BIBLIOGRAPHY}

Baumgartner, W. J. 1904 Some new evidence for the individuality of the chromosomes. Biol. Bull., vol. 8.

Carnoy, J. B. 1885 La Cytodiérése chez les Arthropodes. La Cellule, T. 1.

Carothers, E. E. 1913 The Mendelian ratio in relation to certain orthopteran chromosomes. Jour. Morph, vol. 24.

Davis, H. S. 1908 Spermatogenesis in Acrididae and Locustidae. Bull. Mus. Comp. Zool. Harvard, vol. 53.

St. George, LA VAlette 1887 Zellteilung und Samenbildung bei Forficula auricularia. Festschrift für Kölliker.

Morse, MLAX 1909 The nuclear components of the sex cells of four species of cockroaches. Archiv für Zellforschung, vol. 3.

Randolph, H. 1908 On the spermatogenesis of the earwig, Anisolabis maritima. Biol. Bull., vol. 15.

Schreiner, A. und K. E. 1906 Neue Studien über die Chromatinreifung der Geschlechtszellen. I. Archiv de Biol., Bd. 22.

Sinety, R. de 1901 Recherches sur la Biologie et l'Anatomie des Phasmes. La Cellule, T. 19.

Stevens, N. M. 1908 The chromosomes of Diabrotica. Jour. Exp. Zool., vol. 5. 1910 An unequal pair of heterochromosomes in Forficula. Jour. Exp. Zool., vol. 8

Sutron, W. S. 1902 On the morphology of the chromosome groups of Brachyostola magna. Biol. Bull., vol. 4.

Wilson, E. B. 1905 Studies on chromosomes. II. Jour. Exp. Zool., vol. 2. 1909 The chromosomes of Metapodius. Jour. Exp. Zool., vol. 6.

Zweiger, H. 1906 Die Spermatogenese von Forficula auricularia. Zool. Anz., Bd. 30. Also Jenaische Zeitschrift, Bd. 42. 


\section{PLATE I}

\section{EXPLANATION OF FIGURES}

1 Nucleus in growth period.

2 to 11 Stages in the opening up of a longitudinally split thread to form a ring. 12 to 17 Shows twisting and bending in opening to form a ring.

18 to 24 Different stages of ring formation in the same chromosome by bending and the condensation of this ring into a bivalent chromosome.

25 to 30 Ring formation by bending in another chromosome. 


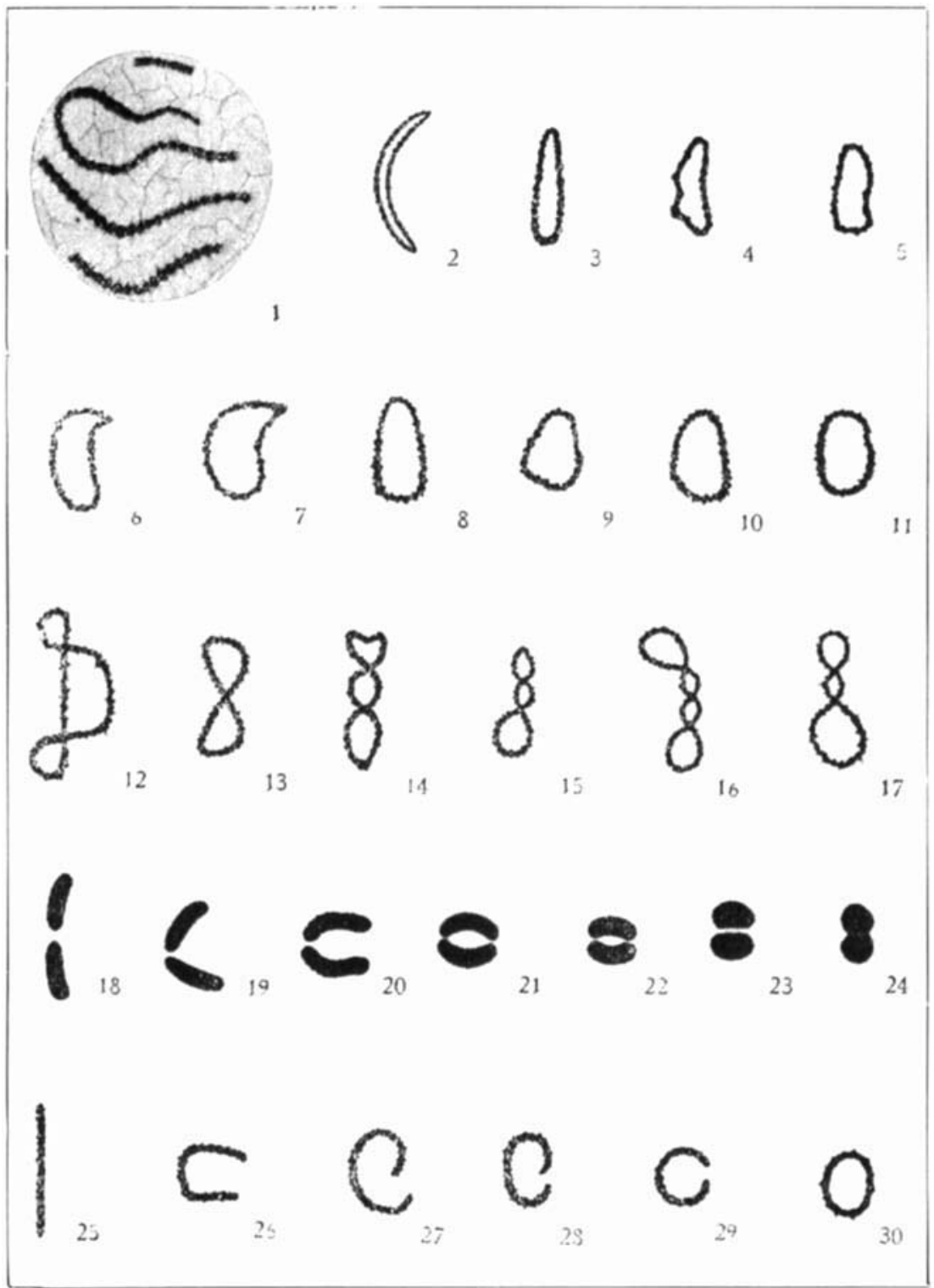




\section{PLATE' 2}

\section{EXPLANATION OF FIGURES}

1 to 10 Successive stages of ring formation by bending in a third chromosome. 11 The three small chromosomes which can be recognized in later prophases of the first division.

12 to 13 Two stages of ring formation in the small chromosomes shown in 11.

14 to 15 Two stages in chromosome formation in these same small chromosomes without ring formation.

16 to 18 Stages of ring formation by bending in another chromosome.

19 Early prophase of the first spermatocyte division showing the presence of an elongated chromosome in which are two oval bodies. These serve as recognition marks.

20 to 24 Stages of ring formation in the chromosome shown in $19 . \quad$ In 20 it is joined end to end to another chromosome.

26 to 27 Two stages showing that the above chromosome (19) may condense into a bivalent without passing through the ring stage. 


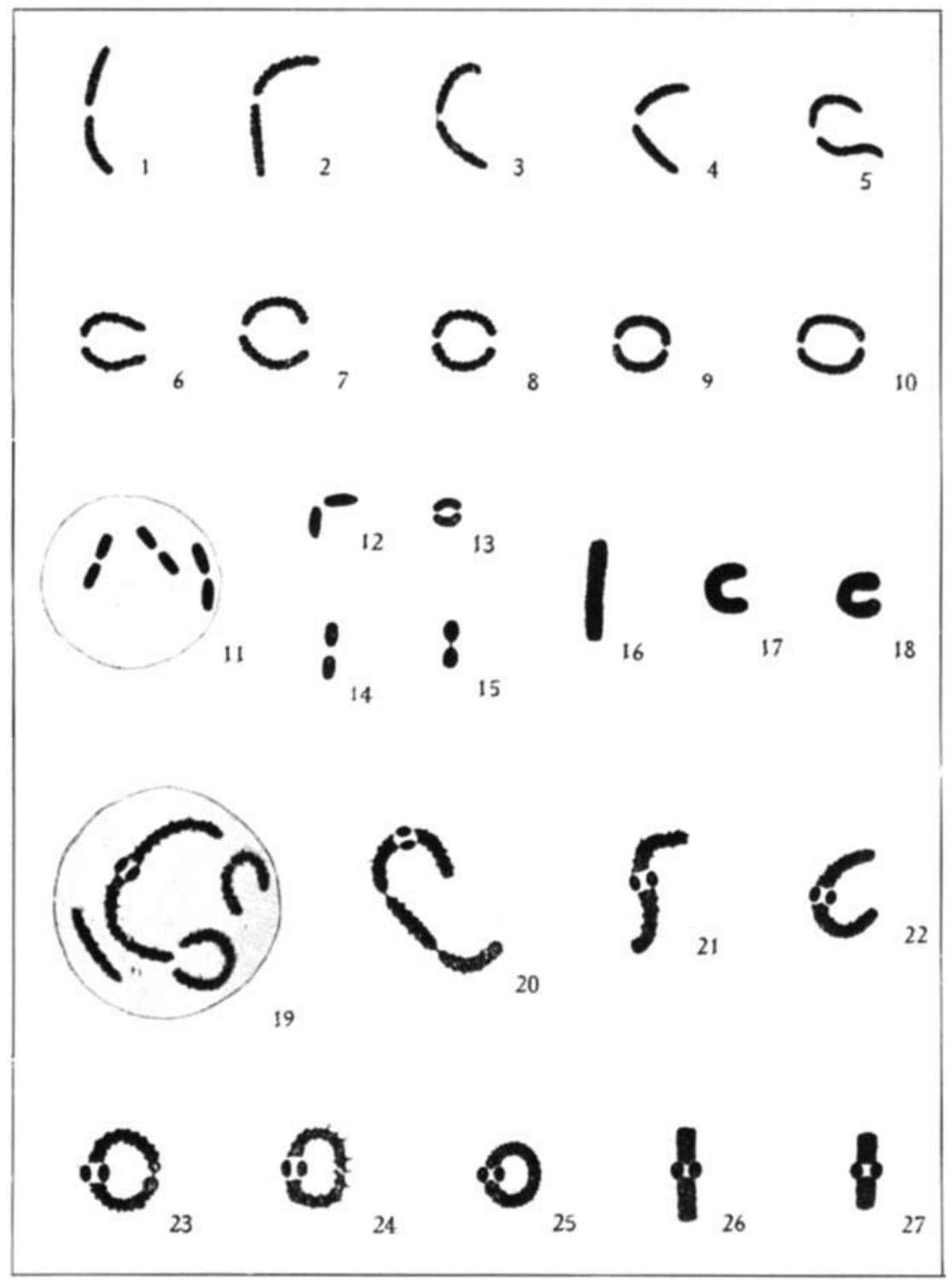

